\title{
The Oxygen Evolution Reaction at Manganese oxide Films in Base: Kinetics \& Mechanism
}

Michelle P. Browne, Ronan J. Cullen, Richard L. Doyle, Paula E. Colavita and Michael E.G. Lyons

Trinity Electrochemical Energy Conversion \& Electrocatalysis (TEECE) group, School of Chemistry \& CRANN (Centre for Research on Adaptive Nanostructures and

Nanodevices), Trinity College Dublin, Dublin 2, Ireland.

\begin{abstract}
Various manganese oxide type Dimensionally Stable Anode

(DSA) electrodes were prepared though a simple thermal decomposition technique at different annealing temperatures for their effect on the oxygen evolution reaction (OER). Along with the change in different annealing temperatures, the effects of different metal substrates were also explored. Cyclic

Voltammetry was used to analyze the redox transitions of all annealing temperatures on the nickel and titanium substrates. Steady state polarization curves (also known as Tafel Plots) were used to determine tafel slopes, Open Circuit Potential decay analysis was also used to determine tafel slopes. Reaction orders of the $350^{\circ} \mathrm{C}$ nickel $\mathrm{Mn}_{\mathrm{x}} \mathrm{O}_{\mathrm{y}}$ electrode were determined and calculated as a half reaction order. A mechanism for this electrode is also proposed. SEM-EDX and FTIR analysis are also reported on some $\mathrm{Mn}_{\mathrm{x}} \mathrm{O}_{\mathrm{y}}$ films and powders.
\end{abstract}

\section{Introduction}

Currently the interest in developing an alternative to fossil fuels has increased dramatically in recent years due to the imminent threat of the depletion of the earth's coal, oil and gas reserves. As a consequence, the costs of these fossil fuels have also increased. Another disadvantage associated with fossil fuels is the issue of carbon based emissions from the fossil fuels when burnt into the earth's atmosphere which leads to global warming. Many renewable alternatives have already been developed as fossil fuel alternatives e.g. wind power, solar power and hydropower. However all these alternatives may not suit people in different parts of the planet due varied geological/weather conditions being unreliable. Alkaline water electrolysis has been proposed as one of the solutions to this problem; the equations for this process are shown below;

$$
\begin{array}{lll}
\text { Anode: }(\mathrm{OER}) 40 \mathrm{H}^{-} \longrightarrow 2 \mathrm{H}_{2} \mathrm{O}+\mathrm{O}_{2}(\mathrm{~g})+4 \mathrm{e}^{-} & \mathrm{E}^{\circ}=+0.40 \mathrm{~V} \\
\text { Cathode: }(\mathrm{HER}) & 4 \mathrm{H}_{2} \mathrm{O}+4 \mathrm{e}^{-} \longrightarrow 2 \mathrm{H}_{2}(\mathrm{~g})+4 \mathrm{OH}^{-} & \mathrm{E}^{\circ}=-0.83 \mathrm{~V}
\end{array}
$$

$$
\text { Overall: } 2 \mathrm{H}_{2} \mathrm{O} \longrightarrow 2 \mathrm{H}_{2}(\mathrm{~g})+\mathrm{O}_{2}(\mathrm{~g}) \quad \mathrm{E}^{\circ}=-1.23 \mathrm{~V}
$$


The cathodic process produces large amounts of hydrogen gas which can then be used in vital applications such as energy conversion and energy storage devices. In contrast to the use of fossil fuels, the production of hydrogen, as an energy source, from alkaline water electrolysis offers an environmentally inoffensive and reliable route to the production of the large volumes of hydrogen gas required by a possible hydrogen economy (1-3).

Of course during water electrolysis oxygen is also produced at the anode, according to equation 1 above, the production of oxygen is the main energy consuming step in the reaction. In practice, the efficiency of water electrolysis is limited by the large anodic over-potential of the oxygen evolution reaction (OER) (3). Thus, a vast amount of research is being dedicated into fully understanding the kinetics and mechanism of the OER reaction. This knowledge should lead to the development of an OER anode material that produces oxygen at the lowest overpotential.

Currently there are various electrodes being studied for the oxygen evolution reaction, these include thermally prepared DSA type oxide electrodes, electrochemically prepared hydrous oxide electrodes, and electrodeposited bulk oxide/hydroxide electrodes using various metal oxides (4). In this work DSA type electrodes are examined. DSA electrodes were first used by the chlori-alkai industry. These electrodes consist of a titanium support which was then coated with a mixed metal oxide (5). The optimum oxide materials for the preparation of these electrodes are $\mathrm{RuO}_{2}$ and $\mathrm{IrO}_{2}$ due to their ability to produce oxygen at the lowest overpotential compared to other metal oxides. However these materials are highly expensive and do not exhibit long term stability in alkaline water electrolysis conditions (5). Much interest into the use of the first row transition metals ( $\mathrm{Mn}, \mathrm{Fe}, \mathrm{Ni}$ and $\mathrm{Co}$ ) have been reported for OER anode material due to their good electrochemical performance and their long tern stability in alkaline media (4).

In recent years manganese oxide has been studied as an alternative anodic material for alkaline water electrolysis due to its relative low cost, eco-friendly properties and long term corrosion resistance in alkaline solution compared to $\mathrm{RuO}_{2}$ and $\mathrm{IrO}_{2}$ (6).

Manganese oxides electrodes can be produced/synthesized in various ways such as Electrodeposition (7), Chemical precipitation (8), Sol-gel (9) and by Thermal Decomposition (10). In this communication, the behaviour of thermally decomposition prepared DSA type manganese oxide electrode as an OER anode material will be reported.

\section{Experimental Details}

\section{$\underline{\text { Preparation of electrodes }}$}

The working electrodes in this work were prepared via a thermal decomposition method outlined by Trasatti et al. (9) To prepare the electrodes titanium (as supplied by Alfa Aesar- Johnson Matthey company, purity 99.99\% (metals basis), with a diameter of $1.0 \mathrm{~mm}$ ) or nickel wire (as supplied by Alfa Aesar- Johnson Matthey company, purity 99.99\% (metals basis)) were sealed in glass. The electrodes were then dipped in 5M $\mathrm{H}_{2} \mathrm{SO}_{4}$, polished with 1200 grit carbimet paper and washed with deionised water and set aside to dry. A $0.01 \mathrm{M} \mathrm{Mn}_{\mathrm{x}} \mathrm{O}_{\mathrm{y}}$ precursor solution was made from dissolving $\mathrm{Mn}\left(\mathrm{NO}_{3}\right)_{2} \cdot \mathrm{H}_{2} \mathrm{O}$ in a $10 \mathrm{ml}$ conical flask, which was weighed using a weighing balance (Sartorius, model 1872). The resulting mixture was evaporated on a hot plate (Jenway 
hotplate and stirrer, model 1000) until a black/brown slurry was observed. Deionised water was then added to the slurry to form a paste (will be referred to as $\mathrm{Mn}_{\mathrm{x}} \mathrm{O}_{\mathrm{y}}$ paste), which was then used to paint onto either the titanium or nickel wires that were used as the working electrodes, which were previously prepared.

The annealing treatment applied in this research consisted of painting the working electrode with one coat of the $\mathrm{Mn}_{\mathrm{x}} \mathrm{O}_{\mathrm{y}}$ paste and dried in an oven at $90^{\circ} \mathrm{C}$ for ten minutes in air. Another coat of the $\mathrm{Mn}_{\mathrm{x}} \mathrm{O}_{\mathrm{y}}$ paste was coated onto the electrode and annealed in air, in a second oven, for 4 hours. A number of samples were prepared at various annealing temperatures on both titanium and nickel substrates. This is illustrated in figure 1 below;

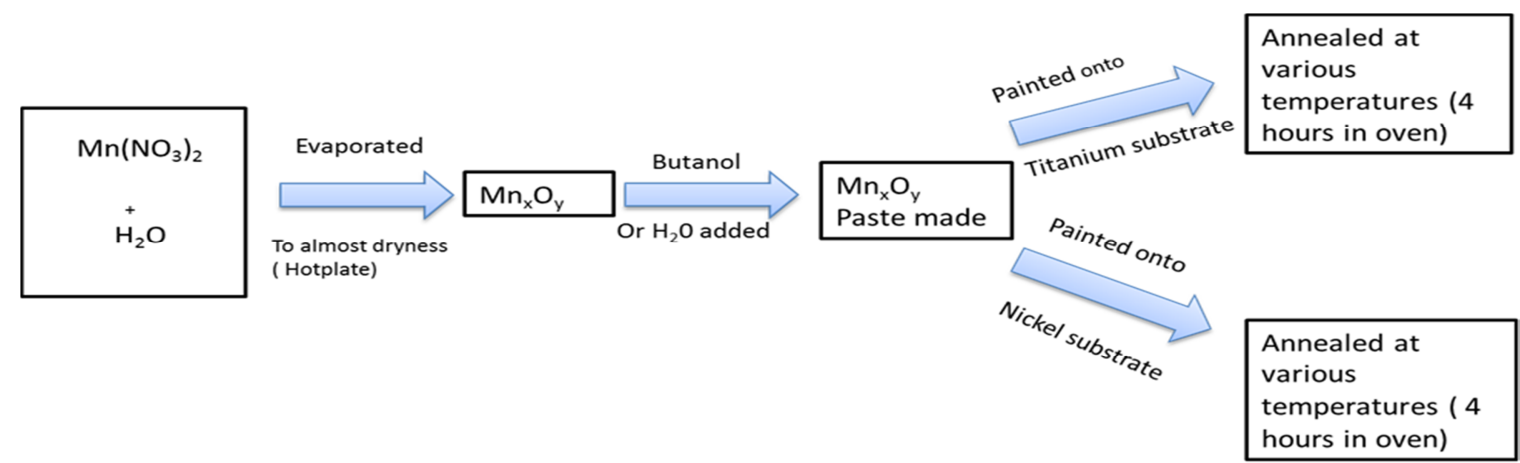

Figure 1: Experimental schematic of the preparation of the $\mathrm{Mn}_{\mathrm{x}} \mathrm{O}_{\mathrm{y}}$ Films

\section{Electrochemical testing analysis methodology}

All electrochemical experiments were undertaken in a standard three electrode cell. The working electrodes consisted of the titanium or nickel film substrate with $\mathrm{Mn}_{\mathrm{x}} \mathrm{O}_{\mathrm{y}}$ paste annealed at different temperatures, as described above. A graphite rod was employed as a counter electrode and a mercury-mercuric oxide $(\mathrm{Hg} / \mathrm{HgO})$ reference electrode ( $\mathrm{CH}$ instruments, cat no. 152) was utilized as a reference standard ${ }^{1}$, therefore all potentials are quoted against this reference electrode. The various electrolyte solutions used for the redox behavior studies of the $\mathrm{Mn}_{\mathrm{x}} \mathrm{O}_{\mathrm{y}}$ films including tafel slope analysis and reaction order studies with respect to the hydroxide ion $\left(-\mathrm{OH}^{-}\right)$, were prepared from sodium hydroxide $(\mathrm{NaOH})$ pellets (Sigma-Aldrich, $\geq 98 \%$ purity, reagent grade). The $\mathrm{NaOH}$ electrolyte solutions concentrations ranged from $0.01 \mathrm{M}$ to $5 \mathrm{M}$.

The electrochemical measurements were performed using high performance digital potentiostats including a $\mathrm{CH}$ model $1760 \mathrm{D}$ Bi-potentiostat system monitored by the CH1760D electrochemical workstation beta software or an Autolab PGSTAT302N potentiostat/ galvanostat monitored by the Nova 1.8 Autolab software. Cyclic Voltammetric experiments were ran in aqueous $1.0 \mathrm{M} \mathrm{NaOH}$ at $100 \mathrm{mV} \mathrm{s}^{-1}$ between limits of $-2.0 \mathrm{~V}$ and $+2.0 \mathrm{~V}$ vs. $\mathrm{Hg} / \mathrm{HgO}$ reference electrode. Tafel plot measurements

1 The equilibrium potential of the cell $\mathrm{Pt} / \mathrm{H} 2 / \mathrm{OH}-/ \mathrm{HgO} / \mathrm{Hg}$ is $0.926 \mathrm{~V}$ at $298 \mathrm{~K}$. Since the equilibrium oxygen electrode potential is $1.229 \mathrm{~V}$ vs RHE, it follows that the corresponding value is $0.303 \mathrm{~V}$ vs. $\mathrm{Hg} / \mathrm{HgO}$ in the same solution. Hence $\mathrm{E}_{\mathrm{Hg} / \mathrm{HgO}}=\mathrm{E}_{\mathrm{RHE}}-0.926 \mathrm{~V}$. It is a common practice in the literature on the OER to express potential in terms of the oxygen overpotential $n$, when the reference electrode is a $\mathrm{Hg} / \mathrm{HgO}$ electrode in the same solution as the working anode. Clearly, in this case the overpotential $n$ is related to Emeas measured on the $\mathrm{Hg} / \mathrm{HgO}$ scale as follows: $n=$ Emeas $-0.303 \mathrm{~V}$ (at $\mathrm{T}=298 \mathrm{~K}$ ) 
were performed at a sweep rate of $1 \mathrm{mV} \mathrm{s}^{-1}$ in the forward oxidation direction. For tafel plot measurements the uncompensated solution resistance was usually determined at a 90\% compensation level. All tafel plot data is presented in iR compensated form.

\section{Electrochemical Impedance measurements}

The electrochemical impedance measurements were performed using high performance digital potentiostats including a $\mathrm{CH}$ model $1760 \mathrm{D}$ Bi-potentiostat system monitored by the CH1760D electrochemical workstation beta software. The electrochemical impedance measurements were ran in $1 \mathrm{M} \mathrm{NaOH}$ at a fixed potential of $-0.1 \mathrm{~V}$.

\section{SEM-EDX measurements}

The morphological characteristics of the DSA MnxOy type electrodes were carried out by a SEM Karl Zeiss Ultra at an accelerating voltage between $15 \mathrm{KV}-2 \mathrm{KV}$ and a working distance between $9 \mathrm{~mm}-5 \mathrm{~mm}$.

\section{FTIR analysis}

Fourier Transform Infrared Spectroscopy analysis was also carried out on the DSA MnxOy electrode with a Spectrum 100 FTIR spectrometer using Spectrum software to record the data. The spectrum was recorded in the range between $4000 \mathrm{~cm}^{-1}$ and $500 \mathrm{~cm}^{-1}$.

\section{Results}

In the present work, we focus on the redox properties and electrocatalytic behaviour with respect to anodic oxygen evolution of manganese dioxide electrodes in aqueous alkaline solution. The redox behaviour of the resulting oxide films is investigated as a function of substrate and annealing temperature using Cyclic Voltammetry. Interestingly, the voltammetric profile for the manganese dioxide film is strongly dependent on the nature of substrate, as evident from Figure 2.

\section{$\underline{\text { Redox characteristics - Nickel and titanium substrate }}$}

The change in annealing temperatures exhibits a different voltammetric profile for the same metal substrate which could be due to different Manganese compounds being formed due to the different temperatures applied to the manganese oxide solution painted on the substrate, as shown from Fig. 2.

According to Hong et al. if pure manganese nitrate is exposed to $250^{\circ} \mathrm{C}, 600^{\circ} \mathrm{C}$ degrees and $1000^{\circ} \mathrm{C}$ the manganese compounds which are produced are $\mathrm{MnO}_{2}, \mathrm{Mn}_{2} \mathrm{O}_{3}$ and $\mathrm{Mn}_{3} \mathrm{O}_{4}$ respectively(11), these chemical equations are shown below;

$$
\mathrm{Mn}\left(\mathrm{NO}_{3}\right)_{2} \cdot 6 \mathrm{H}_{2} \mathrm{O} \longrightarrow \mathrm{MnO}_{2}+\mathrm{N}_{2} \mathrm{O}_{4}+6 \mathrm{H}_{2} \mathrm{O}
$$

Heating the manganese dioxide at approximately $600^{\circ} \mathrm{C}$ and $1000^{\circ} \mathrm{C}$ temperatures allows for the loss of oxygen to produce $\mathrm{Mn}_{2} \mathrm{O}_{3}$ and $\mathrm{Mn}_{3} \mathrm{O}_{4}$;

$$
\begin{aligned}
& 6 \mathrm{MnO}_{2} \longrightarrow 3 \mathrm{Mn}_{2} \mathrm{O}_{3}+\frac{3}{2} \mathrm{O}_{2} \\
& 3 \mathrm{Mn}_{2} \mathrm{O}_{3} \longrightarrow 2 \mathrm{Mn}_{3} \mathrm{O}_{4}+\frac{1}{2} \mathrm{O}_{2}
\end{aligned}
$$


Table 1 shows the different oxidation states of the various manganese compounds formed at the different temperatures. Oxidation numbers have been assigned to the corresponding $\mathrm{Mn}_{\mathrm{x}} \mathrm{O}_{\mathrm{y}}$ compound from Pourbaix diagrams hence possible redox transition states can be assigned to the different annealing temperatures (12);

TABLE I. Oxidation numbers of corresponding manganese compounds at different annealing temperatures from literature.

\begin{tabular}{ccc}
\hline $\mathbf{M n}_{\mathbf{x}} \mathbf{O}_{\mathbf{y}}$ Compound & Oxidation number (12) & Annealing temperature $\left({ }^{\circ} \mathrm{C}\right)(11)$ \\
\hline $\mathrm{MnO}_{2}$ & +4 & 250 \\
$\mathrm{Mn}_{2} \mathrm{O}_{3}$ & +3 & 600 \\
$\mathrm{Mn}_{3} \mathrm{O}_{4}$ & +2.67 & 1000 \\
\hline
\end{tabular}
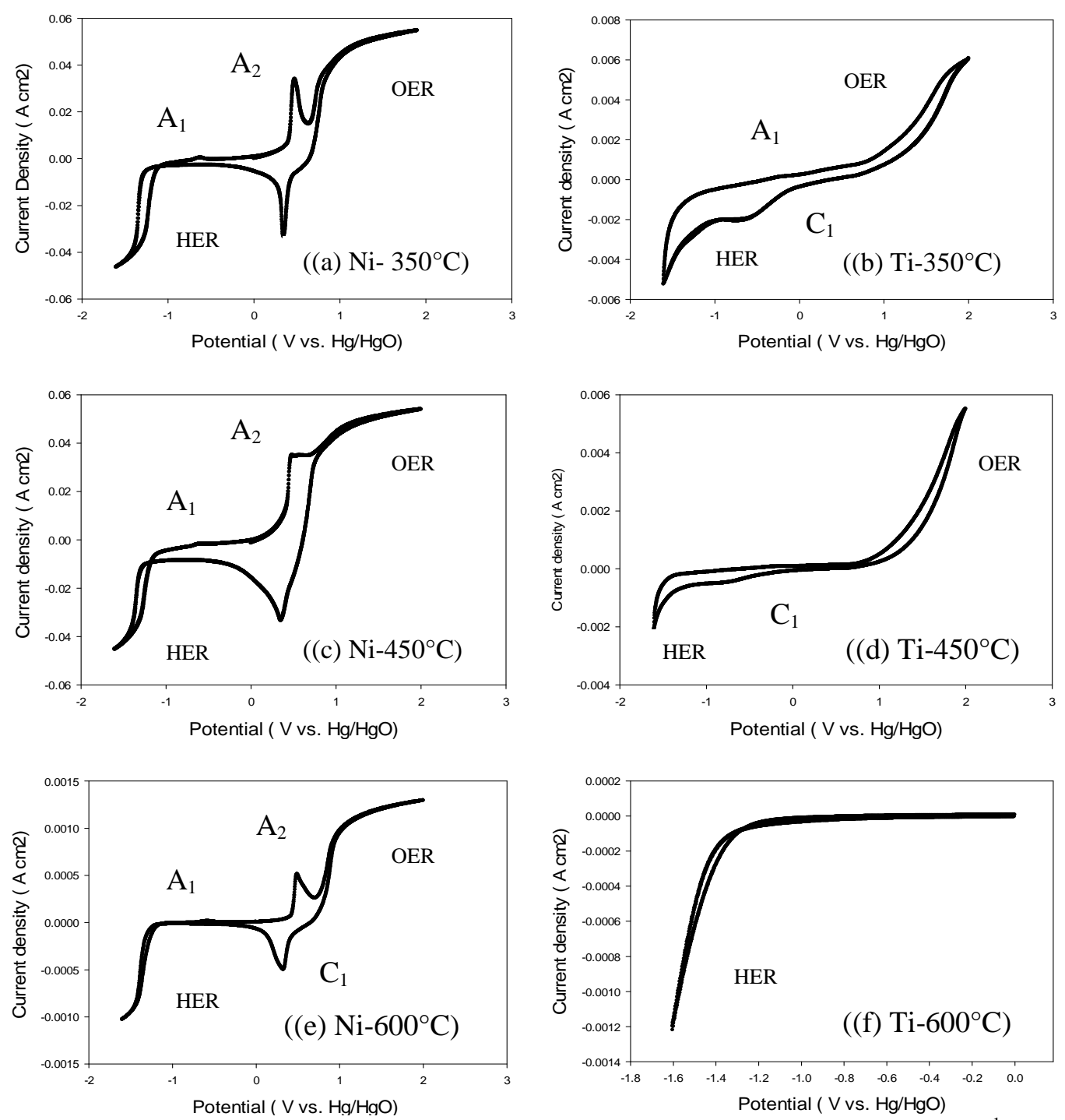

Figure 2: Typical CV response recorded in $1.0 \mathrm{M} \mathrm{NaOH}$ at a sweep rate of $100 \mathrm{mVs}^{-1}$ for ((a) Ni-

$\left.350^{\circ} \mathrm{C}\right)$ nickel film substrate at $350^{\circ} \mathrm{C}$ annealing temperature $\left((\mathrm{b}) \mathrm{Ni}-450^{\circ} \mathrm{C}\right)$ nickel film substrate at $450^{\circ} \mathrm{C}$ annealing temperature and $\left((\mathrm{c}) \mathrm{Ni}-600^{\circ} \mathrm{C}\right)$ nickel film substrate at $600^{\circ} \mathrm{C}$ annealing temperature $((\mathrm{d})$ Ti- $350^{\circ} \mathrm{C}$ ) titanium film substrate at $350^{\circ} \mathrm{C}$ annealing temperature $\left((\mathrm{e}) \mathrm{Ti}-450^{\circ} \mathrm{C}\right)$ titanium film substrate at $450^{\circ} \mathrm{C}$ annealing temperature and $\left((\mathrm{e}) \mathrm{Ti}-600^{\circ} \mathrm{C}\right)$ titanium film substrate at $600^{\circ} \mathrm{C}$ annealing temperature. 
As outlined, the manganese oxide film prepared on the nickel substrate at $350^{\circ} \mathrm{C}$ exhibits two oxidation peaks at $-0.7 \mathrm{~V}\left(\mathrm{~A}_{1}\right)$ which is small compared to the sharp second oxidation peak at $0.45 \mathrm{~V}\left(\mathrm{~A}_{2}\right)$ and one sharp reduction peak at $0.35 \mathrm{~V}\left(\mathrm{C}_{1}\right)$. Similarly the manganese oxide film prepared on the Nickel substrate at $450{ }^{\circ} \mathrm{C}$ has two oxidation peaks and one reduction peak however the first oxidation peak at the potential $-0.7\left(\mathrm{~A}_{1}\right)$ is not as defined as the first oxidation peak at $-0.7 \mathrm{~V}\left(\mathrm{~A}_{1}\right)$ when compared to the manganese film annealed at $350^{\circ} \mathrm{C}$ on nickel. The second oxidation peak compared to the nickel $350^{\circ} \mathrm{C}$ film shows a broader peak and subsequently leads to the onset of oxygen evolution. The oxidation peaks of the $600^{\circ} \mathrm{C}$ on the nickel substrate exhibit two oxidation peaks also at the potentials of $-0.7 \mathrm{~V}\left(\mathrm{~A}_{1}\right)$, which is smaller compared to the nickel $350^{\circ} \mathrm{C}$ and $450^{\circ} \mathrm{C}$, and a sharp second oxidation peak at $0.45 \mathrm{~V}\left(\mathrm{~A}_{2}\right)$ and one sharp reduction peak at 0.35 $\mathrm{V}\left(\mathrm{C}_{1}\right)$. The nickel substrate manganese films all exhibit oxidation and reduction peaks at the same potential however the intensity of the peaks vary with increasing annealing temperature.

In contrast to the manganese oxide film on nickel, the voltammetric responses of the manganese oxide films prepared on the titanium substrate contain less voltammetric characteristics. Another observation is that the titanium oxidation and reduction peaks vary with the change in annealing temperature. The manganese films on titanium at $350^{\circ} \mathrm{C}$ exhibits one oxidation peak at a potential of $-0.3 \mathrm{~V}\left(\mathrm{~A}_{1}\right)$. As well as one reduction peak at the potential of $-0.7 \mathrm{~V}\left(\mathrm{C}_{1}\right)$, the manganese film on titanium at $450^{\circ} \mathrm{C}$ also exhibits this reduction peak at $-0.7 \mathrm{~V}\left(\mathrm{C}_{1}\right)$ however the intensity of the peak has decreased, while at an annealing temperature of $600^{\circ} \mathrm{C}$ there is no reduction peak at $-0.7 \mathrm{~V}$. The manganese film on titanium at $450^{\circ} \mathrm{C}$ and $600^{\circ} \mathrm{C}$ contain no oxidation peaks. As the annealing temperature of the manganese films on titanium increases, the intensity of the peaks decreases, outlined in figure $2(\mathrm{~b})(\mathrm{d})(\mathrm{f})$.

The overall reactions occurring in base between the manganese oxides are rather difficult to interpret. Manganese oxides are widely known to be rather complex and the assignment of the specific manganese species is difficult due to the wide range of oxidation states available for manganese (13). However, we propose the following redox reactions could be taking place between the manganese metal and hydroxide ions at the lower potential of $-0.7 \mathrm{~V}$ :

$$
\begin{gathered}
\mathrm{Mn}+2 \mathrm{OH}^{-} \rightarrow \mathrm{MnO}+\mathrm{H}_{2} \mathrm{O}+\mathrm{e}^{-} \\
\mathrm{Mn}+2 \mathrm{OH}^{-} \rightarrow \mathrm{Mn}(\mathrm{OH})_{2}
\end{gathered}
$$

Due to the production of the $\mathrm{MnO}$ or the manganous hydroxide at the first anodic peak, we suggest that at the second anodic peak the following two intermediate reactions may occur either separately or in unison to produce manganic oxide ;

1. Formation of a mixed oxide intermediate

$$
\begin{gathered}
3 \mathrm{MnO}+2 \mathrm{OH}^{-} \rightarrow \mathrm{Mn}_{3} \mathrm{O}_{4}+\mathrm{H}_{2} \mathrm{O}+\mathrm{e}^{-} \\
2 \mathrm{Mn}_{3} \mathrm{O}_{4}+2 \mathrm{OH}^{-} \rightarrow 3 \mathrm{Mn}_{2} \mathrm{O}_{3}+\mathrm{H}_{2} \mathrm{O}+2 \mathrm{e}^{-}
\end{gathered}
$$


2. Formation of a hydroxide intermediate

$$
\begin{aligned}
& \mathrm{Mn}(\mathrm{OH})_{2}+\mathrm{OH}^{-} \rightarrow \mathrm{Mn}(\mathrm{OH})_{3} \\
& 2 \mathrm{Mn}(\mathrm{OH})_{3} \rightarrow \mathrm{Mn}_{2} \mathrm{O}_{3}+3 \mathrm{H}_{2} \mathrm{O}
\end{aligned}
$$

Furthermore the voltammetric response of the nickel substrate manganese oxide films (figure 2(a)(c)(e)) exhibits the onset of oxygen evolution at a potential of ca. $0.7 \mathrm{~V}$. During the oxygen evolution reaction various redox reactions may occur, we propose the following may take place;

$$
\mathrm{Mn}_{2} \mathrm{O}_{3}+2 \mathrm{OH}^{-} \rightarrow 2 \mathrm{MnO}_{2}+\mathrm{H}_{2} \mathrm{O}+2 \mathrm{e}^{-}
$$

During oxygen evolution the manganese dioxide may interact with the hydroxide ions in the solution to produce manganate ions or permanganate ions

$$
\begin{aligned}
& \mathrm{MnO}_{2}+4 \mathrm{OH}^{-} \rightarrow \mathrm{MnO}^{--}+2 \mathrm{H}_{2} \mathrm{O}+2 \mathrm{e}^{-} \\
& \mathrm{MnO}_{2}+4 \mathrm{OH}^{-} \rightarrow \mathrm{MnO}^{-}+2 \mathrm{H}_{2} \mathrm{O}+1 \mathrm{e}^{-}
\end{aligned}
$$

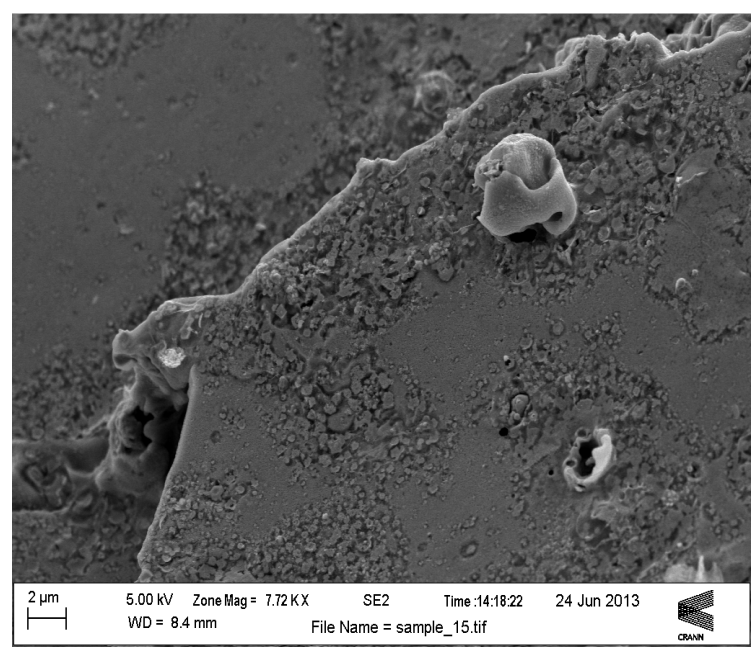

Image 1: SEM of $350^{\circ} \mathrm{C}$ nickel electrode

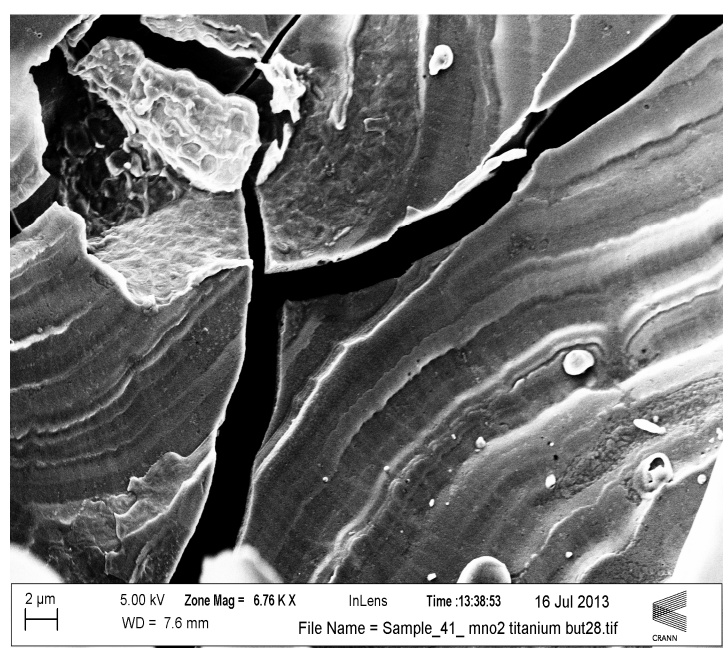

Image 2: $\mathrm{SEM}$ of $350^{\circ} \mathrm{C}$ titanium electrode

When observing the SEM images, image 1 shows the surface morphology of the $\mathrm{Mn}_{\mathrm{x}} \mathrm{O}_{\mathrm{y}}$ on the nickel substrate while image 2 shows the surface morphology of the $\mathrm{Mn}_{\mathrm{x}} \mathrm{O}_{\mathrm{y}}$ on the titanium substrate. Image 1 contains a flakey morphology which appears to cover the surface of the electrode however redox peaks in the cyclic voltammetry, figure 2(a)(c)(e) resembles some of the characteristics of typical hydrous and electrodeposited nickel. However, this simply may be due to cyclic voltammetry being a very powerful analytical tool which has a low detection limit but the accuracy of identification of an analyte is not precise unless the exact analyte is known under known conditions ( i.e. 
$\mathrm{Mn}_{2} \mathrm{O}_{3}$ under ideal conditions) therefore other techniques, such as EDX or X-ray photoelectron spectroscopy(XPS), need to be explored to determine the compound formed on the surface of the electrode from the different annealing conditions. EDX analysis is discussed in this communication. However, XPS, which can determine the oxidation state of the various oxide, is not discussed in this communication but will be pursued as a route of analysis for future work on the manganese oxides. The titanium substrate $\mathrm{Mn}_{\mathrm{x}} \mathrm{O}_{\mathrm{y}}$ electrode exhibits a cracked morphology with wave or ripple like surface. The difference in the morphology of the nickel and titanium substrate $\mathrm{Mn}_{\mathrm{x}} \mathrm{O}_{\mathrm{y}}$ electrodes could indeed play a significant role in the difference in the Tafel analysis conducted on the different electrodes, figure 4(a)(b).

The voltammetric response for the nickel substrate $\mathrm{Mn}_{\mathrm{x}} \mathrm{O}_{\mathrm{y}}$ electrodes, figure 2(a)(c)(e), is very similar to the hydrous and electrodeposited nickel electrodes which are also researched in this group. The similarities include both of these electrodes have one distinct anodic peak but the nickel substrate $\mathrm{Mn}_{\mathrm{x}} \mathrm{O}_{\mathrm{y}}$ electrode has one distinct cathodic peak while the hydrous and electrodeposited nickel usually exhibit two cathodic peaks at potentials close to ca. $0.3 \mathrm{~V}$ and $0.4 \mathrm{~V}$ while the nickel substrate $\mathrm{Mn}_{\mathrm{x}} \mathrm{Oy}$ electrodes exhibits only one distinct sharp cathodic peak can be observed at a potential close to 0.4 $\mathrm{V}$. To determine the elements involved in the voltammetric response SEM-EDX was used.

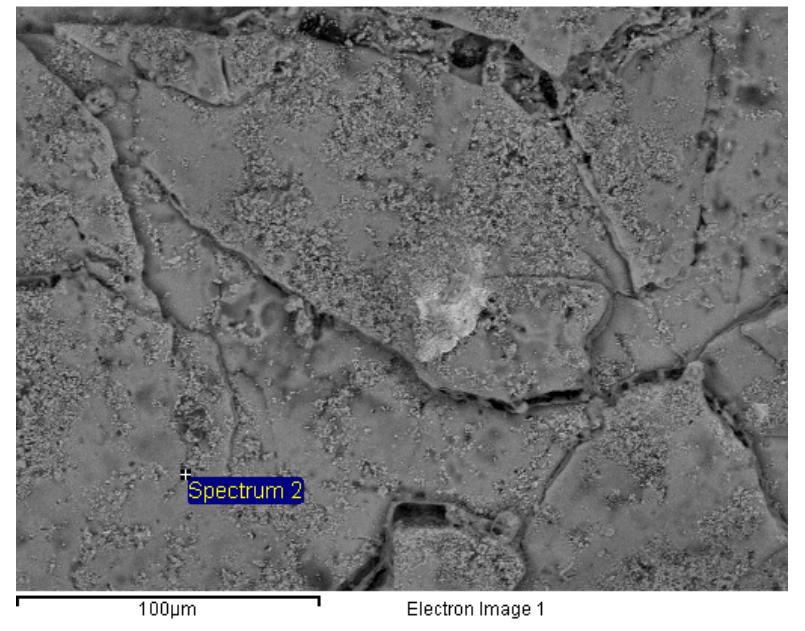

Image 3: $\mathrm{SEM}$ of $350^{\circ} \mathrm{C}$ nickel electrode

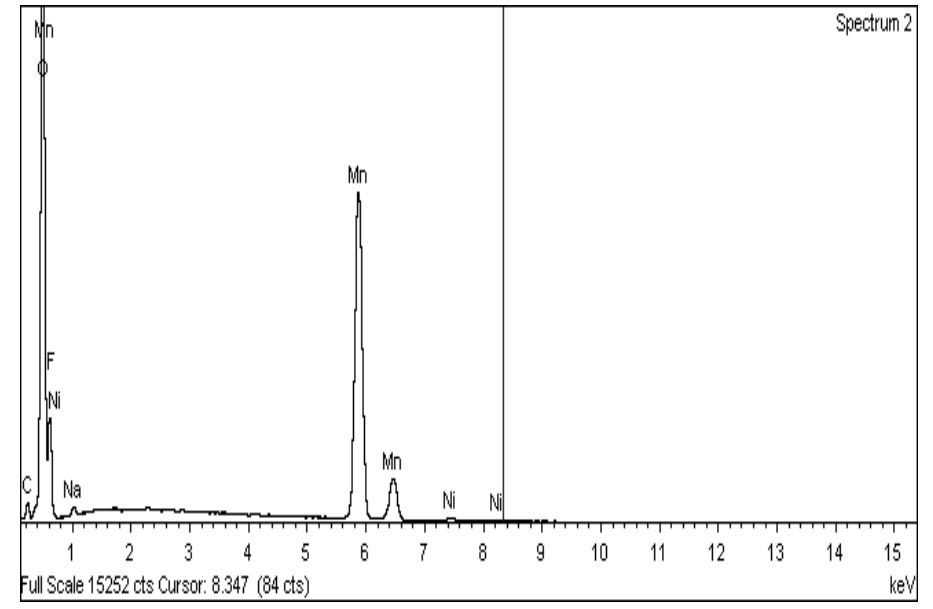

Figure 3: $\mathrm{EDX}$ of $350^{\circ} \mathrm{C}$ nickel electrode

The nickel substrate $\mathrm{Mn}_{\mathrm{x}} \mathrm{O}_{\mathrm{y}}$ electrodes were characterized using SEM-EDX analysis to determine the elemental analysis of the nickel $350^{\circ} \mathrm{C}$ electrode, shown on image 3 and figure 3 above. The EDX results reveal the presence of manganese, oxygen and nickel. The large peak just before $1 \mathrm{keV}$ shows that the manganese and oxygen are present in a much larger quantity than the nickel, which can be seen at about $7.5 \mathrm{keV}$ therefore the voltammetric response shown in figure $2(\mathrm{a})(\mathrm{c})(\mathrm{e})$ could indeed be the voltammetric response of the manganese oxide and not nickel as it does not contain the full voltammetric characteristics of nickel. Similar voltammetric responses for manganese oxides in base have been reported in literature also $(14,15)$. From the literature it is also important to note that the voltammetric response for manganese oxides largely depend on the underlying metal support (15). Other manganese peaks can also be observed at $6 \mathrm{keV}$ and $6.5 \mathrm{keV}$ on the EDX graph. Another interesting feature in the voltammetric 
characteristics of the nickel substrate $\mathrm{Mn}_{\mathrm{x}} \mathrm{O}_{\mathrm{y}}$ electrode is that a hysteresis effect that is observed at the beginning of the hydrogen evolution reaction at a potential close to $-1.2 \mathrm{~V}$, seen in figure 2(a)(c)(e). The voltammetric response shows a unique crossover between the forward and backwards scans which is not seen on a voltammetric response of a hydrous or electrodeposited nickel.

\section{$\underline{\text { OER kinetics and mechanism }}$}

In this section the typical steady sate polarization curves of the MnxOy electrodes on the titanium and nickel substrates at the annealing temperatures of $350^{\circ} \mathrm{C}, 450^{\circ} \mathrm{C}$ and $600^{\circ} \mathrm{C}$ in $1 \mathrm{M} \mathrm{NaOH}$ base are compared, figure $5(\mathrm{a})(\mathrm{b})$. Tafel analysis of a system can be very useful to help and determine mechanistic information of the oxygen evolution reaction through calculating Tafel slopes, which help indicate if various kinetic steps in the reaction are determined by a chemical or an electron transfer steps and can also provide information relating to possible rate determining steps (RDS) for a multistep reaction. To obtain the tafel slopes of a multistep reaction and therefore obtaining the reaction order through the analysis of the steady state polarization curves done as a function of base concentration. The Tafel equation can be arrived following an approach by Bockris and Matthews. A multistep reaction may be considered from the following;

$$
\begin{gathered}
A \leftrightarrow B+e^{-} \text {step } 1 \\
\cdot \quad \cdot \quad \cdot \quad \cdot \\
P \leftrightarrow R+e^{-} \text {step } \vec{n} \\
v\left(R \rightarrow S+n_{r} e^{-}\right) R D S \text { repeated } v \text { times } \\
v S \leftrightarrow T+e^{-} \text {step } n-\vec{n}-n_{r} v \equiv \overleftarrow{n} \\
\cdot \cdot \cdot \cdot \\
Y \leftrightarrow Z+e^{-} \text {step } n
\end{gathered}
$$

Where $\vec{n}$ is the number of electrons transferred before the RDS and $n_{r}$ is the number of electrons transferred after the RDS. $\vec{n}$ can take a value between 0 and 1. If $\vec{n}$ takes a value of 0 and $n_{r}$ takes a value of 1 then this indicates a chemical step prior to the rate determining step predicting a tafel slope of ca. $60 \mathrm{mV} \mathrm{dec}^{-1}$ at $25^{\circ} \mathrm{C}$. If $\vec{n}$ takes a value of 0 and $n_{r}$ takes a value of 1 with $\vec{\alpha}=\beta=\frac{1}{2}$ then this indicates a first electron transfer step prior to the rate determining step which predicts a tafel slope of ca. $120 \mathrm{mV} \operatorname{dec}^{-1}$. Similarly when $\vec{n}$ takes a value of 1 and $n_{r}$ takes a value of 1 with $\alpha=\frac{3}{2}$ this indicates a tafel slope of ca. $40 \mathrm{mV} \mathrm{dec}{ }^{-1}$. Thus, the elucidation of Tafel slopes can be useful in determining possible reaction mechanisms (4).

If the assumption is made that all the steps in the multistep reaction can be described by the simple Butler-Volmer equation and that all the steps before and after the RDS are 
in a state of quasi-equilibrium then the following, more general, Bulter-Volmer equation for a consecutive multi-step reaction can be given by;

$$
i=i_{o}\left\{\exp \left[\left(\frac{\vec{n}}{v}+n_{r} \beta\right) \frac{F \eta}{R T}\right]-\left\{\exp \left[\left(\frac{\vec{n}}{v}+n_{r} \beta\right) \frac{F \eta}{R T}\right]\right\}\right.
$$

Where $i$ is the current density, $i_{o}$ is the exchange current density, $\eta$ is the overpotential and R,F and T have their usual meanings. We can define $\vec{\alpha}=\frac{\vec{n}}{v}+n_{r} \beta$ and $\overleftarrow{\alpha}=\frac{\overleftarrow{\alpha}}{v}(1-$ $\beta) n_{r}$. When is the symmetry factor, generally taken to be $1 / 2$, which arises from the activation of vibrational states and the energy required to break bonds. $v$ is the stoichiometric number defined as the number of times the RDS occurs for one repetition of the overall reaction; therefore the Bulter-Voltmer equation can be simplified to;

$$
i=i_{o}\left\{\exp \left[\frac{\vec{\alpha} F \eta}{R T}\right]\right\}-\left\{\exp \left[\frac{\bar{\alpha} F \eta}{R T}\right]\right\}
$$

which describes the net current for a redox couple. Taking for only an oxidation process, the Bulter-Voltmer equation can be written as;

$$
i=i_{o}\left\{\exp \left[\frac{\vec{\alpha} F \eta}{R T}\right]\right\}
$$

Finally removing the $\mathrm{ln}$ from both sides of the equation the following Tafel equation is given;

$$
\ln \frac{i}{i_{o}}=\frac{\propto F \eta}{R T}
$$

Therefore, a plot of the overpotential $(\eta)$ vs log current ( $\mathrm{l}$ ) can be constructed and the tafel slope,b, can be obtained from $2.303 \mathrm{RT} / \alpha \mathrm{F}$. Tafel analysis assumes steady state therefore the polarization curves are carried out at a scan rate of $1 \mathrm{mV} \mathrm{s}^{-1}$.

It is evident from these curves that the annealing temperature and substrate have an effect on the current recorded at a particular potential, therefore the lower tafel region of each electrode will be different resulting in different tafel slope values. When comparing the two substrates, titanium and nickel, it is evident from the graphs that the nickel substrate provided the $\mathrm{Mn}_{\mathrm{x}} \mathrm{O}_{\mathrm{y}}$ system with the greater ability to provide lower overpotentials and higher log current values when compared to the titanium substrate. To better understand this substrate effect, the ohmic resistance of the electrochemical cell was measured using two different techniques: the built in $\mathrm{CH}$ iR test function and electrochemical impedance spectroscopy. Taking the $\mathrm{Mn}_{\mathrm{x}} \mathrm{O}_{\mathrm{y}}$ titanium annealed at $450^{\circ} \mathrm{C}$ film as an example, the built in $\mathrm{CH}$ iR test was performed in a potential region with no observable faradaic activity and a solution resistance value of $10.3 \Omega$ was obtained. However, electrochemical impedance spectroscopy performed at the same potential suggests that the solution resistance is $3.9 \Omega$. This value was obtained from the high frequency resistive plateau in Figure 4 and is in line with typical values determined in 1.0 $\mathrm{M} \mathrm{NaOH}$ solutions for standard metal electrodes. The discrepancy between these values suggests that an added resistance with a magnitude of ca. $6.4 \Omega$ is being measured by the 
$\mathrm{CH}$ iR test function. This is possibly due to the formation of a thin passive oxide layer on the titanium substrate, giving it semi-conductor properties.

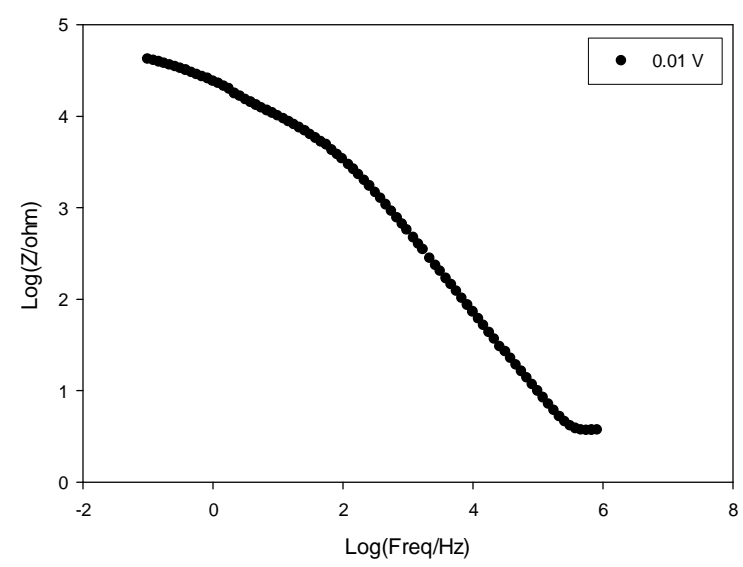

Figure 4: Electrochemical impedance spectrum recorded in the double layer region (-0.1V) for the MnxOy titanium film at $450^{\circ} \mathrm{C}$ annealing temperature in $1 \mathrm{M} \mathrm{NaOH}$ represented in the bode-modulus format.

The tafel slopes for the nickel substrate $\mathrm{Mn}_{\mathrm{x}} \mathrm{O}_{\mathrm{y}}$ vary between $180 \mathrm{mV} \mathrm{dec}{ }^{-1}, 230 \mathrm{mV} \mathrm{dec}^{-}$ ${ }^{1}$ and $330 \mathrm{mV} \mathrm{dec}{ }^{-1}$ while the tafel slopes for the titanium substrate $\mathrm{Mn}_{\mathrm{x}} \mathrm{O}_{\mathrm{y}}$ vary between $444 \mathrm{mV} \mathrm{dec}{ }^{-1}, 1142 \mathrm{mV} \mathrm{dec}^{-1}$ and $3636 \mathrm{mV} \mathrm{dec}^{-1}$ for the electrodes that were annealed at $350^{\circ} \mathrm{C}, 450^{\circ} \mathrm{C}$ and $600^{\circ} \mathrm{C}$ respectfully.
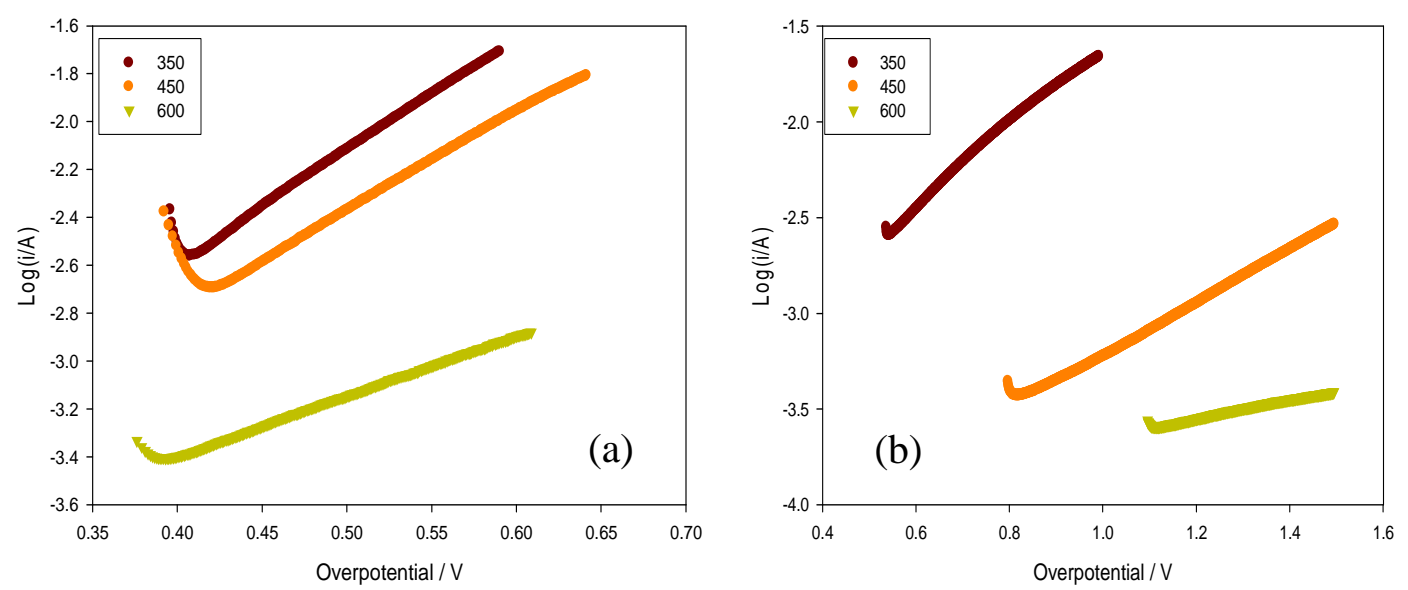

Figure 5:(a) Comparison of Tafel Plots for thermally prepared $\mathrm{Mn}_{\mathrm{x}} \mathrm{O}_{\mathrm{y}}$ on a nickel substrate in $1.0 \mathrm{M} \mathrm{NaOH}$ at a sweep rate of $1 \mathrm{mVs}^{-1}$, (b) Comparison of Tafel Plots for thermally prepared $\mathrm{Mn}_{\mathrm{x}} \mathrm{O}_{\mathrm{y}}$ on a titanium substrate in $1.0 \mathrm{M} \mathrm{NaOH}$ at a sweep rate of $100 \mathrm{mVs}^{-1}$.

From the series of tafel slopes in figure 4(a) and (b) and in table 3 it can be stated the nickel substrate provides greater support for the $\mathrm{Mn}_{\mathrm{x}} \mathrm{O}_{\mathrm{y}}$. The results presented also depict that the optimum temperature to anneal the $\mathrm{Mn}_{\mathrm{x}} \mathrm{O}_{\mathrm{y}}$ electrodes at is 350 degrees, as the current increases at a given potential as the annealing temperature of the electrodes decrease, therefore for the reaction order studies the $\mathrm{Mn}_{\mathrm{x}} \mathrm{O}_{\mathrm{y}}$ electrode at the annealing temperature of $350^{\circ} \mathrm{C}$ on the nickel substrate was chosen. The titanium $\mathrm{Mn}_{\mathrm{x}} \mathrm{O}_{\mathrm{y}}$ electrodes exhibit a large decrease in the initial onset in the OER overpotential with increasing annealing temperature. This could be due to the insulating properties of the titanium support. Literature shows that these oxide type electrodes on a titanium support can 
exhibit a 'mud cracked' structure which allows the titanium metal to interact in the OER mechanism causing an insulating barrier effect thus causing an increase in the electrodes overpotential $(5,16)$. Perhaps with increasing annealing temperature, the $\mathrm{Mn}_{\mathrm{x}} \mathrm{O}_{\mathrm{y}}$ paste on the titanium support becomes more 'mud cracked' allowing for a greater surface area of the titanium metal exposed. Which increases the interaction of the titanium support therefore increases the barrier effect causing the initial overpotential of the OER to increase, which can be observed in figure 5. Further SEM analysis will be done to confirm the surface structure on titanium support with the various annealing temperatures.

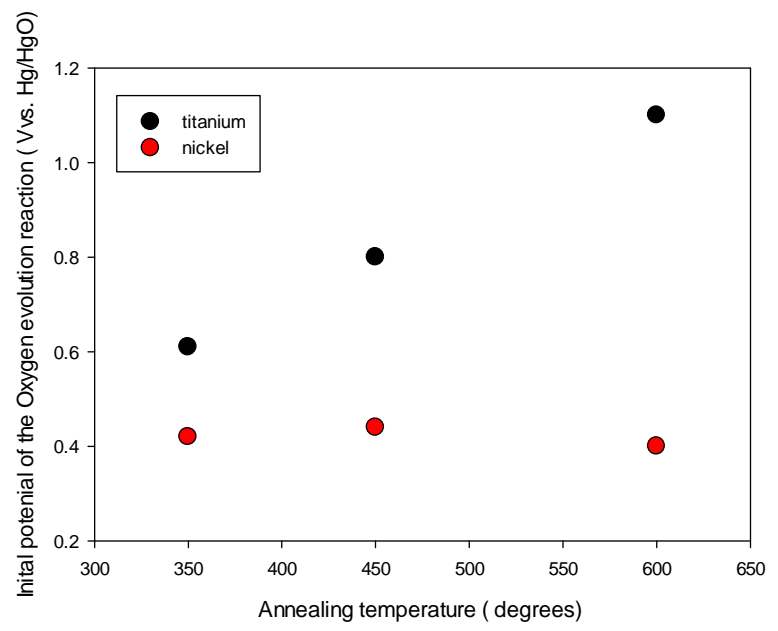

Figure 6: Comparing substrate and annealing temperature

Open circuit potential (OCP) decay curves were used in this work as well as steady state measurements to help determine the kinetics and mechanism of the $\mathrm{Mn}_{\mathrm{x}} \mathrm{O}_{\mathrm{y}}$ electrode in alkaline solutions. Another reason we decided to use OCP analysis was due to the tafel slopes from the steady state analysis being very high. OCP analysis is a very useful technique to employ on metal electrode systems which may undergo alteration on the surface of the electrode over time in strong alkaline solutions.

In this work, OCP analysis is carried out by pre-polarizing the electrode at a potential in the Oxygen Evolution region therefore the electrodes were pre-polarised at a potential of $0.8 \mathrm{~V}$ for a period of time to allow for the system to reach a steady current state. The time allowed for the system to reach steady current depends on the sample. However once a steady current state is achieved then the polarization is switched off and the potential is allowed decay with respect to time and lower and higher tafel slopes can be calculated for the decayed curve.

The tafel slope from the open circuit potential decay curves are calculated under the basis that the slope $-b_{\mathrm{OCP}}$ from the E vs. $\log t$ decay curve is equal to the slope $b$ of the tafel plot for the steady state polarization (4). In general the current density at the electrode can be written as the sum of the charging current $\left(i_{c}\right)$ and the Faradic current $\left(i_{f}\right)$

$$
i=i_{c}+i_{f}
$$

At time $t_{o}$ when the current is switched off, $i=0$ and $\eta=\eta_{0}$ hence, 
Noting that,

$$
i_{c}=-i_{f}
$$

$$
i_{c} d t=d q ; C=\frac{d q}{d V}=\frac{d q}{d \eta_{t}}
$$

Where $q$ is charge and $C$ is capacitance, we can show that,

$$
-i_{f} d t=d t=C d \eta_{t}
$$

Under anodic conditions with $\eta_{t}>R T / F$,

$$
-i_{o} e^{\beta \eta_{t} F / R T} d t=C d n_{t}
$$

Rearranging and integrating gives,

$$
\int_{t_{o}}^{t} i_{o} d t=\int_{\eta_{o}}^{\eta} C e^{-\beta \eta_{t} F / R T} d \eta_{t}
$$

Now, for $t \gg t_{o}$ and $\eta_{o} \gg \eta$,

$$
-i_{o} t=\frac{R T}{\beta F} e^{-\beta \eta_{t} F / R T}
$$

And taking the logarithm gives,

$$
\eta_{t}=\frac{2.303 R T}{\beta F} \log \left(\frac{R T}{\beta F i_{o}}\right)-\frac{2.303 R T}{\beta F} \log (t)
$$

Thus, an equivalent Tafel slope can be determined from the slope of a plot of the measured potential or overpotential during the decay as a function of $\log t$. Typical tafel slope results from OCP analysis for MnxOy films in 1M base can be seen below, figure 6 and table 2 and 3 .
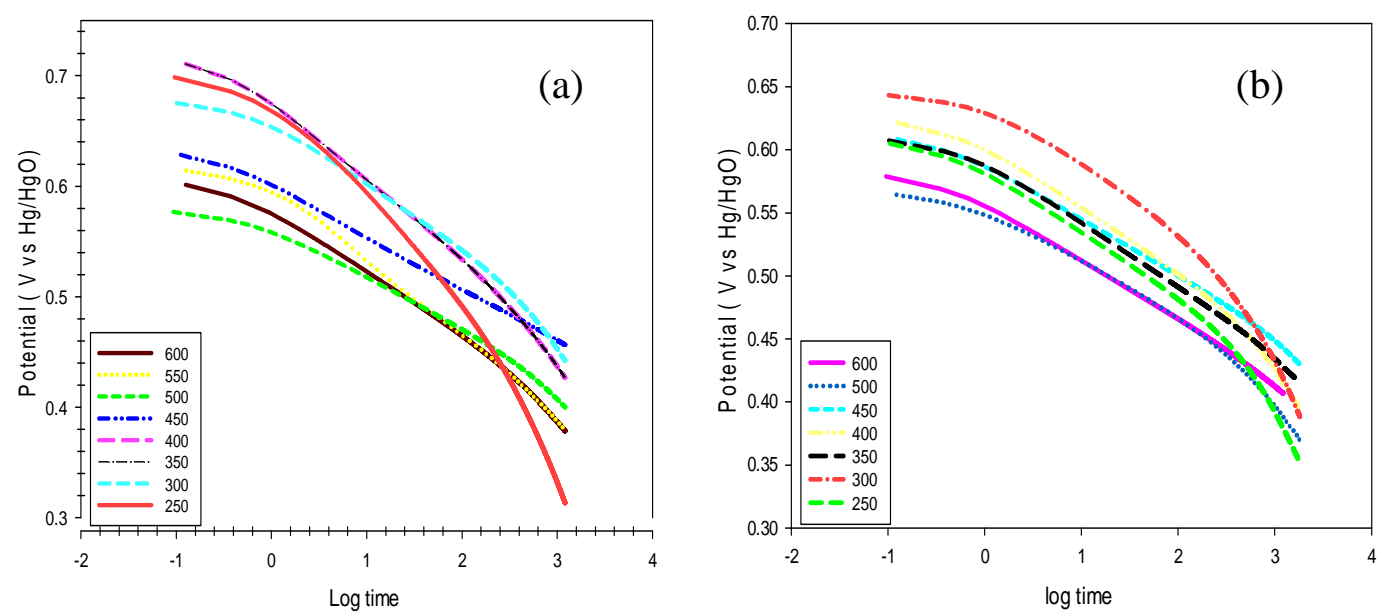

Figure 7: OCP decay curves pre-polarized at $0.8 \mathrm{~V}$ for (a) nickel substrate and (b) titanium substrate for 8 different annealing temperatures in the range of $250^{\circ} \mathrm{C}$ to $600^{\circ} \mathrm{C}$. 
TABLE 2. : OCP tafel slopes on titanium substrate.

\begin{tabular}{ccc}
\hline $\begin{array}{c}\text { Annealing temperature } \\
\text { ( degrees) }\end{array}$ & $\begin{array}{c}\text { Lower Tafel slope } \\
\text { ( } \mathbf{~ m V ~ d e c - 1 )}\end{array}$ & $\begin{array}{c}\text { Higher Tafel slope } \\
\text { ( } \mathbf{~ m V ~ d e c - 1 )}\end{array}$ \\
\hline $\mathbf{6 0 0}$ & $35 \pm 2.1$ & $75 \pm 5$ \\
$\mathbf{5 5 0}$ & $47.5 \pm 5.6$ & $12 \pm 7.4$ \\
$\mathbf{5 0 0}$ & $35 \pm 2.1$ & $113 \pm 11.5$ \\
$\mathbf{4 5 0}$ & $40 \pm 1.3$ & $67 \pm 11.5$ \\
$\mathbf{4 0 0}$ & $42.5 \pm 5.1$ & $115 \pm 8.2$ \\
$\mathbf{3 5 0}$ & $35 \pm 3.3$ & $83 \pm 2.9$ \\
$\mathbf{3 0 0}$ & $40 \pm 3.2$ & $168 \pm 2.9$ \\
$\mathbf{2 5 0}$ & $42.5 \pm 1.7$ & $165 \pm 8.7$ \\
\hline
\end{tabular}

TABLE 3. : OCP tafel slopes on nickel substrate.

\begin{tabular}{ccc}
$\begin{array}{c}\text { Annealing temperature } \\
\text { ( degrees) }\end{array}$ & $\begin{array}{c}\text { Lower Tafel slope } \\
(\mathbf{~ m V ~ d e c - 1 )}\end{array}$ & $\begin{array}{c}\text { Higher tafel slopes } \\
(\mathbf{~ m V ~ d e c - 1 )}\end{array}$ \\
\hline $\mathbf{6 0 0}$ & $13 \pm 2.9$ & $60 \pm 13.2$ \\
$\mathbf{5 5 0}$ & $73 \pm 2.9$ & $110 \pm 5.0$ \\
$\mathbf{5 0 0}$ & $42.5 \pm 3.5$ & $175 \pm 5.0$ \\
$\mathbf{4 5 0}$ & $52 \pm 5.8$ & $90 \pm 0.0$ \\
$\mathbf{4 0 0}$ & $55 \pm 2.9$ & $178 \pm 10.6$ \\
$\mathbf{3 5 0}$ & $63.5 \pm 3.6$ & $109 \pm 2.9$ \\
$\mathbf{3 0 0}$ & $57.5 \pm 2.5$ & $100 \pm 5.0$ \\
$\mathbf{2 5 0}$ & $54 \pm 3.81$ & $113 \pm 2.9$ \\
\hline
\end{tabular}

The difference in the tafel slopes from the OCP measurements and the steady state measurements may arise from the decrease in the concentration of surfaquo* groups, the site of oxygen evolution, as they become reduced as part of the accompanying cathodic process in self-discharge. This relates to the work of Conway and Bourgault, (17) which proposes the relationship between the decay slope and the steady state Tafel slope could be used to determine the potential dependence of the surface capacity and the fractional surface coverage of adsorbed intermediates.

*Hydrated surface species which undergo that undergo rapid redox transformations involving the gain or loss of electrons. These hydrated surfaces are located near the surface of the film [4]. 
At high but not total coverage of intermediates, the surface capacity increases with decreasing potential. The decay slope is therefore given by;

$$
b_{O C P}=\frac{b^{\prime} b}{b^{\prime}-b}
$$

Where $b^{\prime}$ is some positive multiple or fraction of RT/F hence the OCP tafel slope is less than the steady state Tafel slope. Subsequently instead of relating the surface capacity to adsorbed intermediate, Conway and Bourgault, we relate the surface capacity to surfaquo groups or concentration of charged surface. Due to the difference in the OCP slope and the steady state analysis slope it would indicate that the surface capacity changes between the two types of measurements therefore also suggesting that the number of surfaquo groups also changes [4].

\section{$\underline{\text { Reaction order studies- } 350^{\circ} \mathrm{C} \text { nickel }}$}

From the kinetic data shown above from the Tafel analysis and the Open Circuit Potential decay curves the Nickel substrate with $\mathrm{Mn}_{\mathrm{x}} \mathrm{O}_{\mathrm{y}}$ was chosen to undergo reaction order studies as it showed the lowest Tafel slope on steady state analysis of $188 \mathrm{mV} \mathrm{dec}^{-1}$

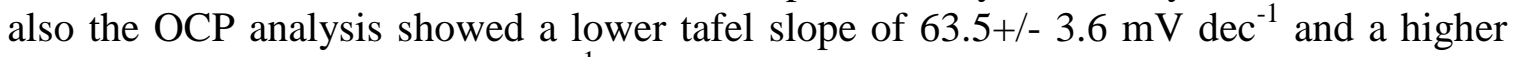
tafel slope of $109+/-2.9 \mathrm{mV} \mathrm{dec}^{-1}$.Steady state tafel plots (figure 6) were recorded as a function of $\mathrm{NaOH}$ base concentration over the range of $5 \mathrm{M}$ to $0.01 \mathrm{M}$.

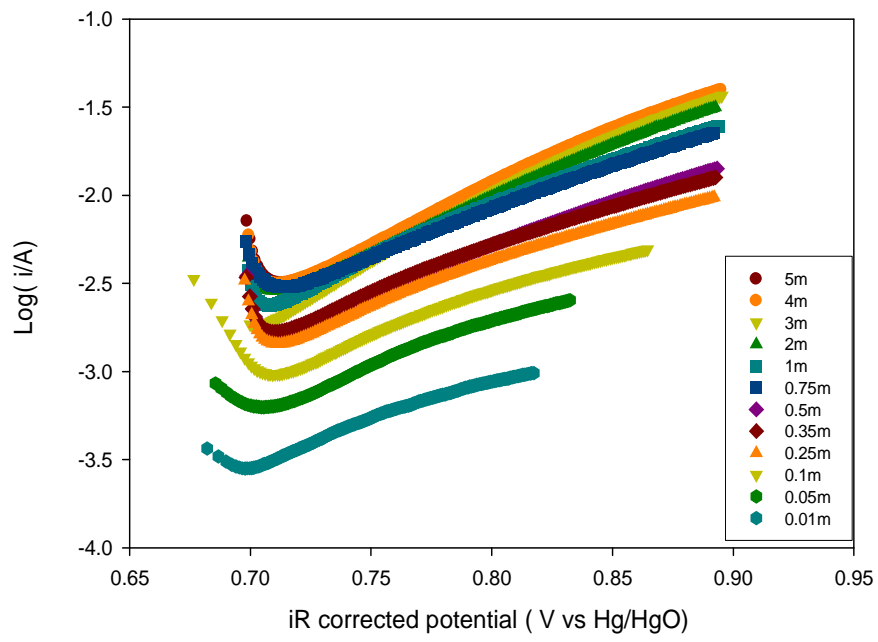

Figure 8: Typical Tafel plots for active oxygen evolution recorded for thermally prepared $\mathrm{Mn}_{\mathrm{x}} \mathrm{O}_{\mathrm{y}}$ material on a nickel substrate as a function of base concentration $(5 \mathrm{~m}-0.01 \mathrm{M})$.

The reaction order studies undergone in this research were analyzed from various potential regions along the active oxygen evolution reaction site and the corresponding $\log$ current value was obtained for varying base concentrations, for the $350^{\circ} \mathrm{C} \mathrm{Mn}_{\mathrm{x}} \mathrm{O}_{\mathrm{y}}$ electrode the potentials chosen to perform the series of reaction order studies are $0.73 \mathrm{~V}$, 
$0.75 \mathrm{~V}$ and $0.78 \mathrm{~V}$. These results are present in the figures 7,8 and 9 below. Interestingly there appears to be two slopes appearing within the reaction orders therefore two reaction orders were calculated; one corresponding to the lower base concentrations $(0.01 \mathrm{M}-1 \mathrm{M})$ and one corresponding to the higher base concentrations (2M-5M).

Three different $\mathrm{Mn}_{\mathrm{x}} \mathrm{O}_{\mathrm{y}}$ electrodes were prepared and reaction order studies were performed using the same nickel wire sealed in glass. The reaction orders were calculated from the following formula;

$$
m_{O H-}=\frac{\delta \log i}{\delta \log a_{O H-}}
$$

Where $i$ is current, $\mathrm{a}_{\mathrm{OH}}$ is the activity of the hydroxyl ion and $\mathrm{m}_{\mathrm{OH}}$ - is the rate of reaction.

$0.73 \mathrm{~V}$

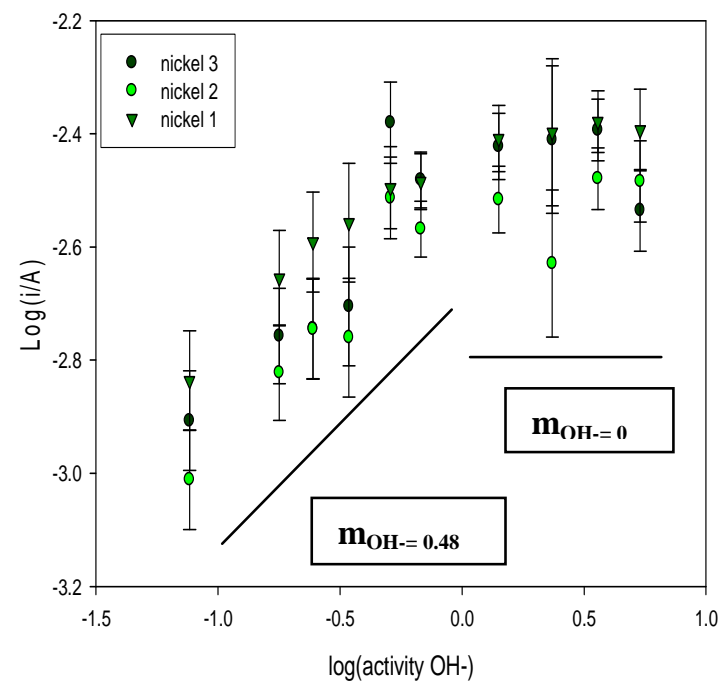

$0.75 \mathrm{~V}$

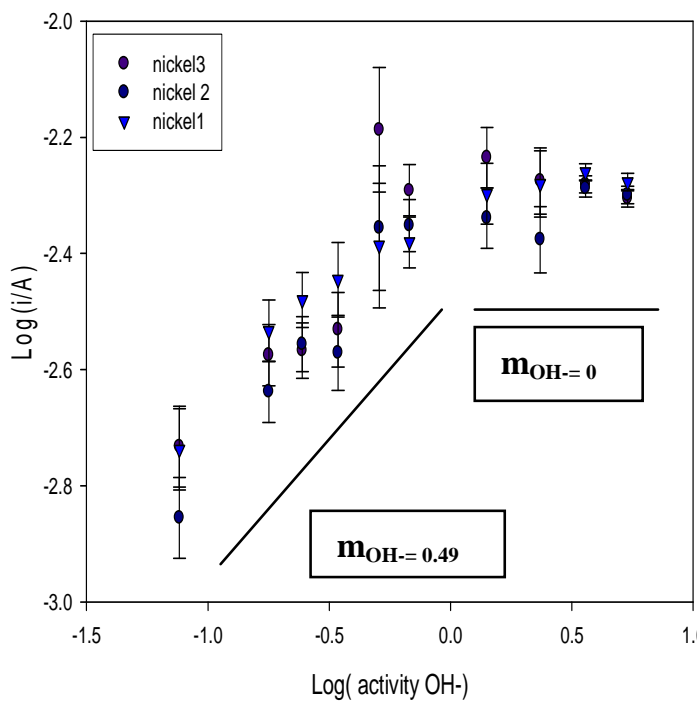

$0.78 \mathrm{~V}$

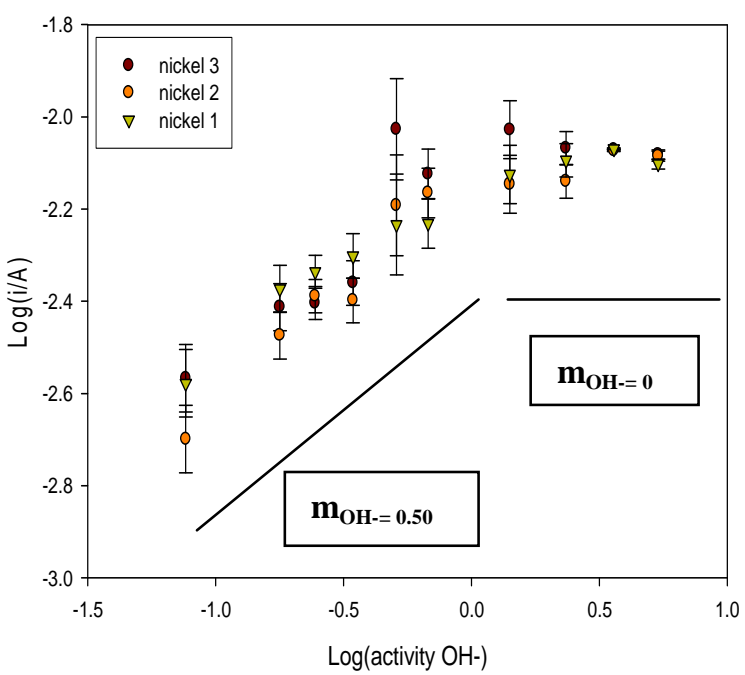

Figure 9: Typical reaction order with respect to oxygen evolution recorded for thermally prepared $\mathrm{Mn}_{\mathrm{x}} \mathrm{O}_{\mathrm{y}}$ material on a nickel substrate (base concentrations $(5 \mathrm{M}-0.01 \mathrm{M})$ ) at $\mathrm{E}=0.73 \mathrm{~V}, 0.75 \mathrm{~V}$ and 0.78 . 
From the reaction orders above it can be stated that the reaction order for the $\mathrm{Mn}_{\mathrm{x}} \mathrm{O}_{\mathrm{y}}$ paste is 0.5 at the lower concentration values. From the errors calculated it suggests that this DSA type electrode is reproducible with the highest deviation between log current value is 0.1304 and the lowest deviation is 0.002 .

\section{$\underline{\text { Mechanism }}$}

The kinetic data obtained from the OCP analysis for the $350{ }^{\circ} \mathrm{C}$ nickel electrode show that the lower tafel slope region are close to $60 \mathrm{mV}$ dec-1 and the higher tafel slope region are close to $120 \mathrm{mV}$ dec- 1 which would indicate that the first step in the reaction mechanism is a chemical transfer step and the second step in the reaction mechanism is the first electron transfer step, with a reaction order of 0.5 at the lower base concentration regions. According to Trassatti et al. fractional reaction orders may be due to the build-up molecules at the surface interface as the molecules are transitioning between acid - base species with the interaction with protonated molecules (OH-) (18).

$\mathrm{S}=$ co-ordinately unsaturated $\mathrm{Mn}$ atom (surfaquo group)

$$
\begin{aligned}
& \text { 1) } \mathrm{S}+\mathrm{OH}^{-} \rightarrow \mathrm{SOH}+e^{-} \\
& \text {2) } \mathrm{SOH}+\mathrm{OH}^{-} \rightarrow \mathrm{SO}^{-}+\mathrm{H}_{2} \mathrm{O} \\
& \text { 3) } \mathrm{SO}^{-} \rightarrow \mathrm{SO}+e^{-}
\end{aligned}
$$

Two equally possible kinetic pathways (19)

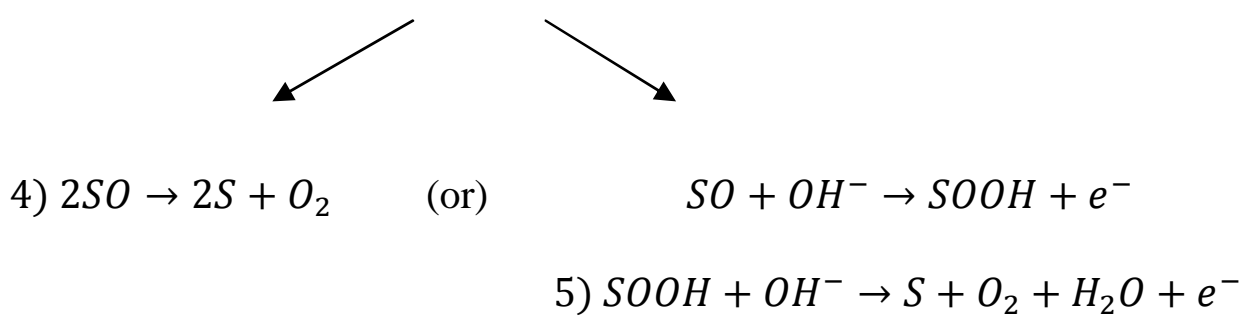

The mechanistic sequence above involves an octahedral geometric molecule consisting of a central manganese atom, also referred to as the surfaquo group(S). The surfaquo group is attached to five ligands and has one free orbital which are all separated by a $90^{\circ}$ angle from each other. At the free orbital attached to the surfaquo group the mechanism proposed above is suspected to take place.

To determine the molecular structure of the $\mathrm{Mn}_{\mathrm{x}} \mathrm{O}_{\mathrm{y}}$ powder annealed at $350^{\circ} \mathrm{C}$ a Fourier Transform Infrared Spectrum was obtained, shown in figure 9. In the fingerprint region of the spectrum, the peaks at $525 \mathrm{~cm}^{-1}$ and $694 \mathrm{~cm}^{-1}$ could arise from stretching vibrations of the $\mathrm{Mn}-\mathrm{O}$ and $\mathrm{Mn}-\mathrm{O}-\mathrm{Mn}$ bonds from the Manganese metal center on the 
octahedral structure to the oxygen ligands attached. The peaks at $3382 \mathrm{~cm}^{-1}$ can be assigned to $-\mathrm{OH}$ stretching vibration along with the peak assigned to $1635 \mathrm{~cm}^{-1}(20)$.

The FTIR analysis suggests that the manganese compound formed, which is involved in the OER mechanism, is either $\mathrm{MnO}_{2}$ or $\mathrm{Mn}_{2} \mathrm{O}_{3}$. Further elemental analysis will have to be conducted to determine the manganese compound formed on the metal support. Subsequently there's a possibility the two of these manganese compounds are formed on the metal support.

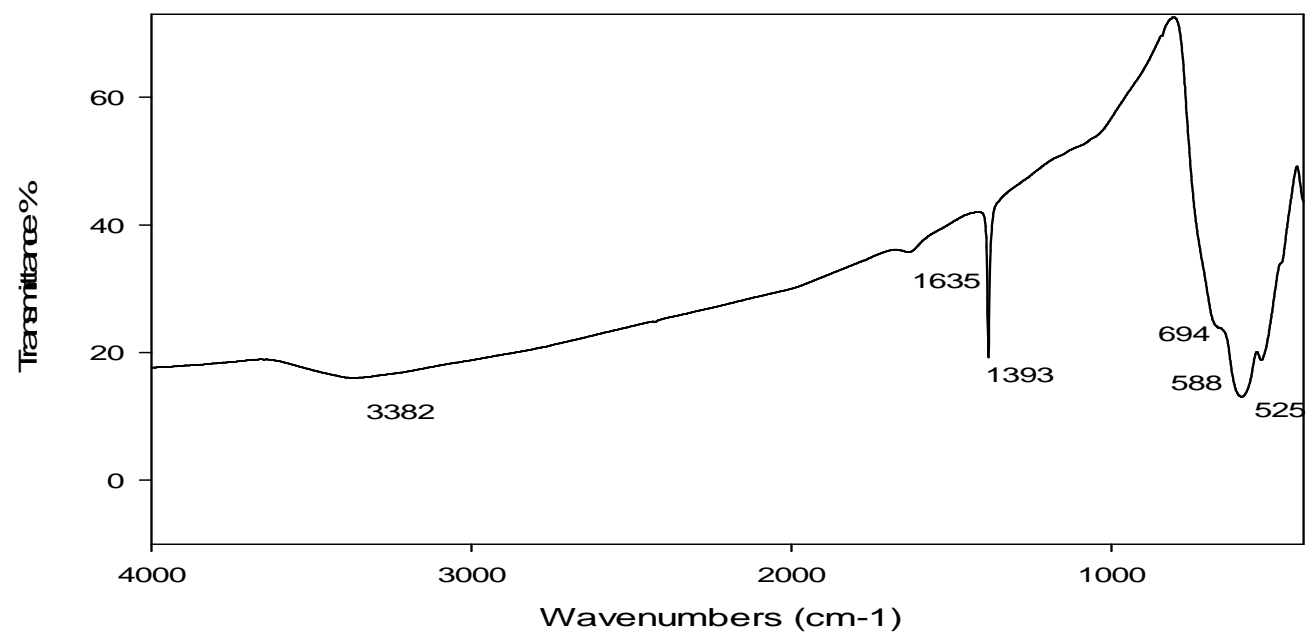

Figure 10: FT-IR of the $350^{\circ} \mathrm{C}$ powder

\section{Conclusion/future work}

The voltammetric profile for the $\mathrm{Mn}_{\mathrm{x}} \mathrm{O}_{\mathrm{y}}$ film is strongly dependent on the nature of substrate. The $\mathrm{Mn}_{\mathrm{x}} \mathrm{O}_{\mathrm{y}}$ film on the nickel substrate exhibits a greatly improved OER performance with respect to oxygen evolution overpotential than the titanium substrate.The reaction orders of the $\mathrm{Mn}_{\mathrm{x}} \mathrm{O}_{\mathrm{y}}$ on the nickel substrate at lower temperatures has exhibited lower tafel slopes and better voltammetric profiles than at higher annealing temperatures on nickel or at any annealing temperature on the titanium substrate. The reaction order of the $\mathrm{Mn}_{\mathrm{x}} \mathrm{O}_{\mathrm{y}}$ film on nickel at 350 degrees is approximately 0.5 at lower base concentrations $(1 \mathrm{M}-0.01 \mathrm{M})$, figure 8 , which shows good reproducibility. Future work with the $\mathrm{Mn}_{\mathrm{x}} \mathrm{O}_{\mathrm{y}}$ system includes more FTIR analysis on the electrodes at the different temperatures and XRD studies to further determine the type and structure of the manganese compounds annealed at the various temperatures which are on a nickel or titanium substrate.

\section{Acknowledgments}

This publication has emanated in part from research conducted with the financial support of Science Foundation Ireland (SFI) under Grant Number SFI/10/IN.1/I2969. 
We would also like to thank the staff at the Advanced Microscopy Laboratory in CRANN for their help in producing SEM images and conducting EDX analysis.

\section{References}

1. K. Zeng and D. Zhang, Prog. Energy Combust. Sci., 36, 307(2010).

2. H. Tributsch, Int. J. Hydrogen Energy, 33, 5911(2008).

3. D. E. Hall, J. Electrochem. Soc., 130, 317(1983)

4. R.L Doyle, I.J Godwin, M.P Brandon and M.E.G Lyons, Phys. Chem. Chem. Phys,Advanced Article(2013).

5. Sonke Schachtel, Martina Toiminen, Kyosti Kontturi, Olof Forsen and Michael H. Barker, J. Appl Electrochem, 39:1835-1848(2009).

6. M.E.G Lyons and S. Floquet, Phys. Chem. Chem. Phys,13,5314-5335(2011).

7. S. Devaraj , N. Munichandraiah,J. Electrochem. Soc.,7,154, A80-A88(2007)

8. J.Wei, M.Cheong, N.Nagarajan, and I.Zhitomirsky, ECS Trans.,3, 37,1-9 (2007).

9.C. Lin, K. Chuang, C. Lin,C. Tsay, C.Chen, Surface and CoatingTechnology,202, 1272-1276(2007).

10. D.Galizzioli, F. Tantardini, S. Trasatti, J. Appl Electrochem ,4,57-67(1974).

11. K.S. Hong,Thermochimica Acta, 381, 153-164(2002).

12. M. Pourbaix, Atlas of Electrochemical Equilibria in Aqueous Solutions, 1966

13. L.D. Burke and O.J. Murphy, J. Electroanal. Chem,109,373-377(1980).

14. R. Renuka, S. Ramamurthy, Journal of Power Sources ,87, 144-152(2000).

15.Fabio H.B. Lima, Marcelo L. Calegaro, Edson A. Ticianelli, Electrochimica Acta, Volume 52, Issue 11, Pages 3732-3738(2007).

16. F Cardarelli , P Taxil, A Savall, J. Appl electrochem,1, 208(1998).

17. B. E. Conway and P. L. Bourgault, Trans. Faraday. Soc., 58, 593(1962).

18. E.Guerrini, H. Chen, S. Trasatti, J. Solid State Electrochem , 11, 939-945(2007).

19. Hai-Yan Su, Yelena Gorlin, Isabela C. Man, Federico Calle-Vallejo, Jens

K. Nørskov, Thomas F. Jaramillo and Jan Rossmeisl, Phys. Chem. Phys. Chem. ,14,14010-14022(2002).

20. Liang, J.Phys. Chem. C, Vol.112, No. 14(2008). 